\title{
Study of Teratogenic Effects of Chitrak (Plumbago-zeylanica) an Ayurvedic Drug on Developing Mice Embryo
}

\author{
Anubha Srivastava ${ }^{1}$, VK Srivastava ${ }^{2}$, G Singh $^{3}$
}

\begin{abstract}
In classical Ayurvedic literature, the root preparation of plant Chitrak (Plumbago-zeylanica) is well documented to be having anti-cancer properties. Away from its use as anti-neoplastic drug, it is also a very common ingredient in so many Ayurvedic formulations which are used as herbal digestive and carminative. Many times they can be prescribed to a pregnant woman also, so the present study is designed to assess the teratogenic effect in mice embryos induced by Chitrak as Ayurvedic medicine. After evaluation of 24 fetuses who have received Chitrakroot powder during their anti-natal life period, it can be said that Chitrak is relatively safe for them; however, only a few fetuses have shown subcutaneous hemorrhages in their necks.
\end{abstract}

Keywords: Chitrak, Anti-neoplastic, Janmabalapravrita, Plumbagin, Plumbago-zeylanica, Ayurveda, Teratogenic

\section{Introduction}

Chitrak, an Ayurvedic preparation, is used for treatment of various tumors and many other diseases. In Ayurvedic formulations, screening through animal model is not practice; therefore, it remains obscure if these medicines are teratogenic or not. In classical Ayurvedic literature, the root preparation of plant Chitrak (Plumbago-zeylanica) is well documented to be having anti-cancer properties. In the present work, an effort has been made to evaluate the teratogenic effect of Chitrak in an animal model, i.e., mice, so as to understand the modus operandi of the action of Chitrak on different tissues of the developing mice embryo.

\section{Teratology}

Teratology stems from the Greek word "Teras" meaning monster or marvel, the discipline, which deals with anomalies. In contemporary usage, the term teratology generally refers to disfiguring birth defects or malformations. Currently, its most instrumental meaning is that of the medical study of teratogenesis, congenital malformations or grossly deformed individuals. With greater understanding of the origins of birth defects, the field of teratology now overlaps with other fields of basic science, including developmental biology, embryology, and genetics. There are a few definitions closely related to explain the term teratology like congenital physical anomaly, congenital malformations, birth defect, genetic disorder, and congenital metabolic diseases.

\footnotetext{
${ }^{1}$ Assistant Professor, Department of Rachana Shareer, Government Ayurveda College \& Hospital, SSVV, Varanasi.

${ }^{2}$ Assistant Professor, Department of Kayachikitsa, Faculty of Ayurveda, IMS, BHU, Varanasi

${ }^{3}$ Emeritus Professor, Department of Anatomy, IMS, BHU, Varanasi

Correspondence: Dr. Anubha Srivastava, Government Ayurveda College \& Hospital, SSVV, Varanasi.

E-mail Id: anubha_27in@yahoo.co.in.

Orcid Id: http://orcid.org/0000-0001-5743-4203

How to cite this article: Srivastava A, Srivastava VK, Singh G.Study of Teratogenic Effects of Chitrak (Plumbago-zeylanica) an Ayurvedic Drug on Developing Mice Embryo. J Adv Res Ayur Yoga Unani Sidd Homeo 2017; 4(1\&2): 46-50.
}

Digital Object Identifier (DOI): https://doi.org/10.24321/2394.6547.201711

ISSN: 2394-6547 


\section{Wilson's Principles}

These principles of teratology were put forth by Jim Wilson in 1959, in his monograph Environment and Birth Defects. These principles guide the study and understanding of teratogenic agents and their effects on developing organisms, studies designed to test the teratogenic potential of environmental agents use animal model systems (e.g., rat, mouse, rabbit, dog, and monkey). Early teratologists exposed pregnant animals to environmental agents and observed the fetuses for gross visceral and skeletal abnormalities. While this is still part of the teratological evaluation procedures today, the field of teratology is moving to a more molecular level, seeking the mechanism(s) of action by which these agents act. Genetically modified mice are commonly used for this purpose. These studies provide information about possible risks of medications or other exposures in human pregnancies. Understanding how a teratogen causes its effect is not only important in preventing congenital abnormalities but also has the potential for developing new therapeutic drugs safe for use with pregnant women. It is estimated that $10 \%$ of all birth defects are caused by a prenatal exposure or teratogen. These exposures include, but are not limited to:

- Medication or drug exposures

- Maternal infections and diseases

- Environmental exposures

- Occupational exposures

Studies have shown that nearly $50 \%$ of pregnant women have been exposed to at least one medication during gestation. A wide range of different chemicals and environmental factors are suspected or are known to be teratogenic in humans and in animals like

1. Ionizing radiation: atomic weapons, radioiodine, radiation therapy

2. Infections: cytomegalovirus, herpes virus, parvovirus B-19, rubella virus (German measles), syphilis, toxoplasmosis, Venezuelan equine encephalitis virus

3. Metabolic imbalance: alcoholism, endemic cretinism, diabetes, folic acid deficiency, hyperthermia, phenylketonuria, rheumatic disease and congenital heart block, virilizing tumors

4. Drugs and environmental chemicals: 13-cis-retinoic acid, isotretinoin, temazepam, nitrazepam, nimetazepam, aminopterin, androgenic hormones, busulfan, captopril, enalapril, chlorobiphenyls (PCBs), Dioxin, coumarin, cyclophosphamide, diethylstilbestrol, diphenylhydantoin (Phenytoin, Dilantin, Epanutin), ethanol, ethidium bromide, etretinate, lithium (Ebstein Anomalies), methimazole, organic mercury, penicillamine, tetracyclines, thalidomide, trimethadione, uranium, methoxyethyl ethers and valproic acid.

Exposure to teratogens can result in a wide range of structural abnormalities such as cleft lip, cleft palate, dysmelia, anencephaly, ventricular septal defect, etc. In most cases, specific agents produce a specific teratogenic response.

\section{Ayurveda Review}

\section{Adibalapravritta Vyadhi (Heredity Disorders)}

Diseases that are produced by the abnormalities of Sukra (sperm) and Shonita (ovum) such as leprosy, hemorrhoids, etc. These are again of 2 types:

- Matrija (Maternal)

- Pitrija (Paternal)

\section{Janmabala Pravritta Vyadhi (Congenital Disorders)}

The diseases that are produced by improper conduct of the mother such as lameness, blindness, deafness, muteness, nasal speech, dwarfness, etc., all by birth. Again these are of two types:

- Rasakrita (produced by faulty drug, diet and life style of the mother)

- Dauhridapacharakrita (produced by non-fulfilling of the desires of the mother during pregnancy)

\section{Drug Review}

\section{Chitrak}

Plumbago-zeylanica (family: Plumbaginaceae) is a perennial shrub. Its roots have been reported to yield Plumbagin and other pigments. Chitrak is a very common ingredient of various classical Ayurvedic formulations, and many times it is prescribed to pregnant women also. It is a well-known drug to treat different metabolic and digestive disorders like indigestion, flatulence, rheumatoid arthritis, sinusitis, diabetes, malignancy, etc.

\section{Botanical Description of Chitrak (Family: Plumbaginaceae)}

- Hindi synonym - Agni, Chita

- English name - Leadwort

- Found all over India, Shrub, 2-4 feet high

- Guna - Laghu, Ruksha, Tikshna

- Rasa-Katu 
- Virya - Ushna

- Vipaka - Katu

- $\quad$ Part used - Root, root bark
- Common preparations - Chitrakadivati, Chitrak Ghrita, Chitrakharitaki, Agnitundivati, Pippalyadichurna, Mustadichurna, Amalakyadichurna, Panchkolachurna

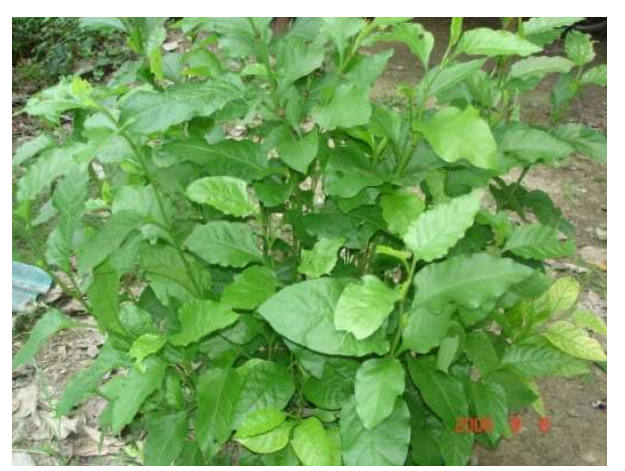

\section{Chemical Studies of Chitrak}

Plumbago-zeylanica roots were found to be devoid of alkaloids and saponins (lyenger \& Pendse, 1962), Plumbago-zeylanica roots have been reported to yield plumbagin and two pigments, viz., 3-chloroplumbagin and 3,3`-biplumbagin (Sindhu \& Sankaran, 1971; Pandey \& Kulkarni, 1973), The root extract was reported to have a binaphthoquinone identified as $3^{\prime}, 6^{`}$-biplumbagin and four pigments identified as isozeylinone, zeylinone, elliptinone and droserone (Sankaran, 1976). There is much evidence to suggest that plumbagin may have potential as a chemotherapeutic or chemopreventive agent. Plumbagin has also been evaluated by the Developmental Therapeutics Program, National Cancer Institute ( $\mathrm{NCl})$, in its screening panel against HIV-1. However, plumbagin is a redox cycling compound that generates superoxide, a reactive species that can damage various bio-molecules. Very limited information on the toxicity of plumbagin raises questions as to whether plumbagin will have too low a margin of safety to exploit its anti-carcinogenic properties. Pure plumbagin is used primarily in research designed to exploit its properties as a superoxide generator, an antibiotic, and an antineoplastic agent. Between 1976 and 1999, 32 patents involving plumbagin were obtained in the United States (US Patent and Trademark Office, 1999).

\section{Chemical and Physical Properties of Plumbagin}

- Description: Yellow needles (Merck, 1997)

- Melting Point: $78-79^{\circ} \mathrm{C}$ (Merck, 1997)

- Solubility: Slightly soluble in hot water; soluble in alcohol, acetone, chloroform, benzene, and acetic acid (Merck, 1997)
- Reactivity: Highly toxic, corrosive (Sigma-Aldrich, 1999)

- Technical Products and Impurities: Plumbagin is available at a purity of $95^{+} \%$ from TCl America (1998) and 99\% from Acros Organics (1997).

\section{Chemical Identification of Plumbagin}

- CAS Registry Number: 481-42-5

- CAS Name: 1,4-Naphthalenedione, 5-hydroxy-2methyl- $(9 \mathrm{Cl})$

- Synonyms and Trade Names: 5-Hydroxy-2-methyl1,4-naphthoquinone; 2-methyl-juglone; plumbagin; plumbagone

- Structural Class: Bicyclic; naphthoquinone

- Molecular Formula: $\mathrm{C}_{11} \mathrm{H}_{8} \mathrm{O}_{3}$

- Molecular Weight: 188.18

\section{Materials and Methods}

In the present study, total 8 mice were undergone for the experimental work. They were divided into two groups, viz., group Band C. The animals were kept properly in respect of macro and micro environments, their diet and water were provided appropriately. The female mice, of average weight of 25-30 gm. and age of 50-60 days (6-8 weeks) were kept with male mice overnight in a separate cage in the ratio of $1: 1$ respectively. The time of mating was established by identification of plug of (mixture of sperm and cellular material from the vagina of the mice) vaginal smear. The gestation period of mice is 19 days, and organogenesis period is between day 6 to day 15 . Hence pregnant females are exposed to Chitrak as teratogene on day 11 , and it is indicated as the dose period for the pregnant mice. 


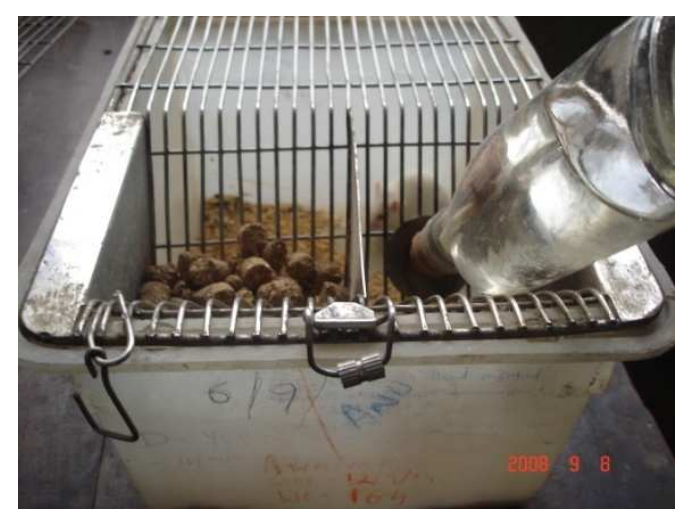

The animals are divided into two groups-

1. Group-B, consisting of 4 mice was administered Chitrak orally on $11^{\text {th }}$ day of gestation in the dose of $100 \mathrm{mg} / \mathrm{kg}$ body weight. The drug was given with $0.5 \mathrm{~mL}$ of distilled water orally with an apparatus.

2. Group-C, the second group consisting of 4 mice; distilled water was given as vehicle is control.

Animals of both groups were sacrificed on day 18 of gestation and fetuses were collected. These were examined through dissecting microscope and naked eye for external malformation. The fetuses made dry by wiping with blotting paper; fetuses were weighed and Crown-Rump length (by sliding calipers) measured.

\section{Observation}

Fetuses were collected on day 18 of gestation by laparotomy. The fetuses were kept in $10 \%$ neutral formalin after weighing and examining them individually for any external malformation. The treated fetus of mice showed a few gross malformations; however, in course of time histology of treated fetus brain, liver, kidney, heart will be done and observation will be carried out. Histological examination of the organs will be carried out using following technique - fixation, dehydration, clearing, wax impregnation, section cutting, staining and mounting.

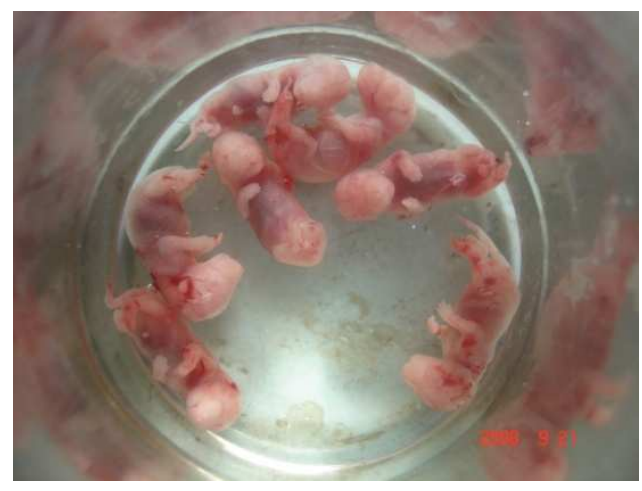

Table 1.Showing Incidence of Fetal C-R length in Group B \& C

\begin{tabular}{|c|c|c|c|c|c|}
\hline Group & Number of Mother Mice & Number of Fetuses & Mean of C-R Length in cm. & S.D. of Length & P Value \\
\hline B & 4 & 24 & 1.85 & \pm 0.12 & \\
\cline { 1 - 5 } C & 4 & 28 & 1.87 & \pm 0.07 & B vs C \\
\cline { 1 - 5 } Total & 8 & 52 & 1.83 & \pm 1.08 & $\mathrm{P}=>0.01$ \\
\hline
\end{tabular}

Table 2.Incidence of Fetal Body Weight in Group B and C

\begin{tabular}{|c|c|c|c|c|c|}
\hline Group & $\begin{array}{c}\text { Number of Mother } \\
\text { Mice }\end{array}$ & $\begin{array}{l}\text { Number of } \\
\text { Fetuses }\end{array}$ & $\begin{array}{l}\text { Mean of Fetal Body Weight in } \\
\text { gm. }\end{array}$ & $\begin{array}{l}\text { S.D. of } \\
\text { Weight }\end{array}$ & P Value \\
\hline B & 4 & 24 & 1.25 & \pm 0.043 & \multirow{3}{*}{$\begin{array}{c}\text { B vs C } \\
P= \\
<0.05\end{array}$} \\
\hline C & 4 & 28 & 1.33 & \pm 0.062 & \\
\hline Total & 8 & 52 & 1.22 & \pm 0.158 & \\
\hline
\end{tabular}




\section{Gross Changes}

\section{Observations}
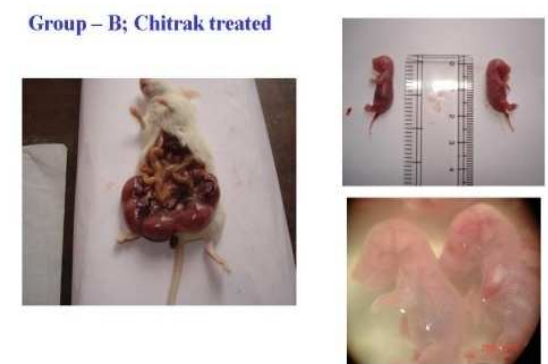

\section{Discussion}

The term teratology is coined from modern medical science but its description is already told in Ayurveda, with reference to classification of diseases. According to Acharya Sushruta and Vagbhata, Janmabalapravrita diseases are very much similar to congenital birth defects as per the etio-pathology and clinical presentation. The present study is designed to evaluate the teratogenic potential of famous Ayurvedic drug Chitrak, which is also known for its anti-tumor activity. On comparing control group with Chitrak-treated group, the length of fetuses was reduced but the data were non-significant. The difference in weight is significant. Further, there was no gross anomaly observed in both the groups; however, stunted growth, sub cutaneous and deep hemorrhage, kinking of tail, protrusion of back of head is observed in a few Chitrak-treated group fetuses.

\section{Conclusion}

Ayurveda is the pivot of all medical sciences and the concept of teratology was there in the ancient Ayurvedic treatises. They have described so beautifully the classification of diseases which are at par with the modern system of therapeutics. After evaluating the whole above exercise, it is quite right to say that Ayurvedic drug Chitrak is extensively used in pregnant women as a herbal digestive, carminative and antineoplastics quite safer, than other chemotherapeutics of modern medicine.

\section{Conflicts of interest: Nil}

\section{Observations}

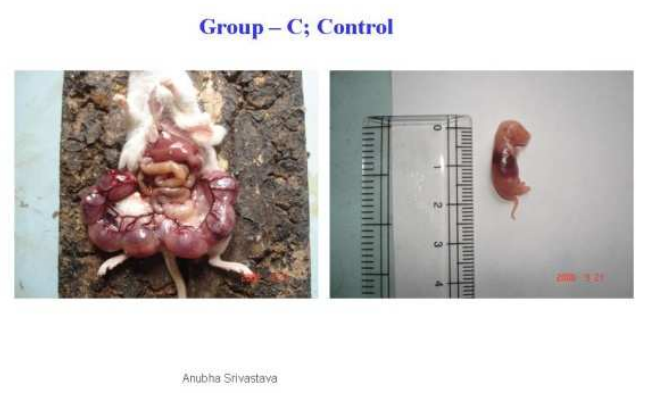

\section{References}

1. Birth Defects \& Genetics: Birth Defects. Retrieved on 2007-05-30.

2. Dicke JM. Teratology: principles and practice. Med. Clin. North Am. 1989; 73(3): 567-82.

3. $a b$ Ronan O'Rahilly, Fabiola Müller. Human embryology \& teratology. New York: Wiley-Liss 2001.

4. James G. Wilson. Environment and Birth Defects (Environmental Science Series). London: Academic Pr 2001.

5. Bracken MB, Holford TR. Exposure to prescribed drugs in pregnancy and association with congenital malformations. Obstetrics and gynecology 1981; 58(3): 336-44.

6. King CR. Genetic counseling for teratogen exposure. Obstetrics and Gynecology 1986; 67(6): 843-46.

7. Linnainmaa K. Sister chromatid exchanges among workers occupationally exposed to phenoxy acid herbicides 2,4-D and MCPA. Teratog. Carcinog. Mutagen. 1983; 3(3): 269-79.

8. Vaglenova J, Birru S, Pandiella NM et al. An assessment of the long-term developmental and behavioral teratogenicity of prenatal nicotine exposure. Behav. Brain Res 2004; 150(1-2): 159-70.

9. Hunt JR. Teratogenicity of high vitamin A intake. $N$. Engl. J. Med 1996; 334(18): 1197.

10. Upadhyay Y. Charaksamhita Part-I. Chaukhambha Publication 2004.

11. Shastri A. Sushrutasamhita Part-I. Chaukhambha Publication 2002. 